\title{
Pregnancy-related changes in Doppler gradients and left ventricular mechanics in women with subvalvular or valvular aortic stenosis.
}

\author{
Soohyun Chang ${ }^{1}$, Parm Khakh², Mikyla Janzen², Marla Kiess² ${ }^{2}$ Valerie Rychel², and \\ Jasmine Grewal ${ }^{3}$ \\ ${ }^{1}$ The University of British Columbia Department of Medicine \\ ${ }^{2}$ The University of British Columbia Faculty of Medicine \\ ${ }^{3}$ The University of British Columbia
}

June 20, 2021

\begin{abstract}
Background: The aim of our study was to characterize echocardiographic changes during pregnancy in women with known LVOT obstruction or AS compared to the healthy pregnancy controls, and to assess the relationship with pregnancy outcomes. Methods: We retrospectively studied 34 pregnant patients with congenital LVOT obstruction or AS with healthy age-matched pregnant controls. Patients with other significant valvular lesions, structural heart disease (LVEF <40\%), or prior valve surgery were excluded. All LVOTO/AS patients underwent a minimum of 2 consecutive echocardiograms between 1 year preconception up to 1 year postpartum, with at least 2 studies during the pregnancy. Comprehensive echocardiographic evaluation was performed including speckle-tracking LV global longitudinal strain. Results: A total of 83 echocardiograms from the study group and 34 echocardiograms from the control group were evaluated. Over the range of LVOTO/AS, a significantly greater increase in the $\mathrm{AV}$ gradients and LV and LA volumes were observed as compared with the controls. In the sub-group of LVOTO/AS pregnant women with $>$ moderate $(\mathrm{n}=8)$ vs.
\end{abstract}

Pregnancy related changes in Doppler gradients and left ventricular mechanics in women with subvalvular or valvular aortic stenosis.

Soohyun A. Chang ${ }^{1}$ MD, Parm Khakh², B.Sc, Mikyla Janzen ${ }^{1}$, MSc, Marla Kiess ${ }^{1}$, MD, Valerie Rychel, $\mathrm{MD}$, Jasmine Grewal ${ }^{1}$, MD

Division of Cardiology, St Paul's Hospital, University of British Columbia, Vancouver, British Columbia, Canada. 1081 Burrard St 4th Floor Burrard Building Rm 44, Vancouver, BC.

University of British Columbia Faculty of Medicine, 317, 2194 Health Sciences Mall, Vancouver, BC.\# Corresponding author:

Dr. Jasmine Grewal

The Division of Cardiology

University of British Columbia St. Paul's Hospital

478 - 1081 Burrard Street

Vancouver, British Columbia

Canada V6Z 1Y6 
jasmine.grewal@vch.ca

Telephone: 604-806-8785

The authors declare no conflict of interest.

\section{ABSTRACT}

Background: The aim of our study was to characterize echocardiographic changes during pregnancy in women with known LVOT obstruction or AS compared to the healthy pregnancy controls, and to assess the relationship with pregnancy outcomes.

Methods: We retrospectively studied 34 pregnant patients with congenital LVOT obstruction or AS with healthy age-matched pregnant controls. Patients with other significant valvular lesions, structural heart disease (LVEF $<40 \%$ ), or prior valve surgery were excluded. All LVOTO/AS patients underwent a minimum of 2 consecutive echocardiograms between 1 year pre-conception up to 1 year postpartum, with at least 2 studies during the pregnancy. Comprehensive echocardiographic evaluation was performed including speckletracking LV global longitudinal strain.

Results: A total of 83 echocardiograms from the study group and 34 echocardiograms from the control group were evaluated. Over the range of LVOTO/AS, a significantly greater increase in the AV gradients and LV and LA volumes were observed as compared with the controls. In the sub-group of LVOTO/AS pregnant women with $>$ moderate $(\mathrm{n}=8)$ vs. $<$ moderate LVOTO $/ \mathrm{AS}(\mathrm{n}=26)$, averaged $2^{\text {nd }} / 3^{\text {rd }}$ trimester LVEF was lower $(51(12) \%$ vs. $58(4) \%, \mathrm{p}=0.02)$ and GLS was lower (-19.5(2.8) vs. $-21.2(2.4), \mathrm{p}=0.06)$. Pregnancy was well tolerated despite these changes.

Conclusion: Among pregnant women with even milder forms of LVOTO/AS, increases in cardiac volumes and AV gradients can be expected over the course of pregnancy. Significant decreases in LV function and mechanics were only observed in women with moderate or greater LVOTO/AS, although still remained in normal range.

Keywords: Speckle tracking echocardiography, global longitudinal strain, left ventricular outflow tract obstruction, aortic stenosis, pregnancy.

\section{Abbreviations}

2D-STE $=$ Two-dimensional speckle tracking echocardiography

$\mathrm{AS}=$ Aortic stenosis

$\mathrm{AR}=$ Aortic regurgitation

$\mathrm{AVA}=$ Aortic valve area

$\mathrm{BSA}=$ Body surface area

$\mathrm{BMI}=$ Body mass index

$\mathrm{CHD}=$ Congenital heart defect

$\mathrm{CO}=$ Cardiac output

$\mathrm{CoA}=$ coarctation of the aorta

$\mathrm{GA}=$ Gestational age

GLS $=$ Global longitudinal strain

$\mathrm{LV}=$ Left ventricular

$\mathrm{LVEF}=$ Left ventricular ejection fraction

LVOT $=$ Left ventricular outflow tract 
LVOTO $/ \mathrm{AS}=$ Left ventricular outflow tract obstruction

$\mathrm{SV}=$ Stroke volume

\section{INTRODUCTION}

Left ventricular outflow tract obstruction (LVOTO/AS) malformations account for approximately $14 \%$ of all congenital heart disease $(\mathrm{CHD})^{1,2}$. Types of lesions include subaortic membrane, bicuspid aortic valve, and supravalvular aortic stenosis. These may occur individually or in association with other anomalies such as coarctation of aorta or hypoplastic left heart ${ }^{3}$. All lesions result in varying degrees of systolic flow obstruction from the left ventricle (LV) to the ascending aorta ${ }^{4}$.

Pregnancy is a state of increased physiologic demand and profound hemodynamic changes which results in increased preload and cardiac output ${ }^{5-7}$. As such, valvular Doppler gradients are expected to increase with normal pregnancy. While women with LVOTO/AS are routinely assessed with echocardiography throughout preconception and pregnancy, there is a paucity of knowledge regarding the impact of pregnancy on LVOTO/AS and what can be considered a physiological vs. pathological change ${ }^{8-10}$. Furthermore, this has not been studied in conjunction with sub-clinical changes in left ventricular function measured by global longitudinal strain (GLS), which has emerged as an important measure of subclinical left ventricular dysfunction with a prognostic role in patients with cardiac disease ${ }^{11-14}$. In particular, among patients with moderate AS or asymptomatic severe AS and preserved LVEF, impaired left ventricular GLS has been shown to be associated with increased risk for progression and a marker for earlier intervention ${ }^{15-18}$.

The objectives of this study were to determine among women with congenital LVOTO/AS: 1) changes in LVOT Doppler gradients over the course of pregnancy and postpartum as compared to controls; 2) changes in left ventricular function evaluated by left ventricular ejection fraction (LVEF) and GLS over the course of pregnancy and postpartum as compared to controls; and 3) if there is an association between LVOT Doppler gradients and left ventricular function with clinical outcomes.

\section{MATERIALS AND METHODS}

\section{Study Population}

A single-center retrospective study was conducted using the Cardiology Obstetrics (COB) database at St. Paul's Hospital (Vancouver, Canada). Consecutive, retrospective pregnancies were identified with established diagnosis of congenital LVOTO/AS (bicuspid aortic valve; bicuspid aortic valve/aortic coarctation; subvalvular aortic stenosis; and bicuspid aortic valve/sub-valvular stenosis) who underwent singleton pregnancy between February 2008 and December 2020. In order to be included, each pregnant woman had to have at least 2 comprehensive transthoracic echocardiograms (TTE) during index pregnancy, each performed during a different trimester. Exclusion criteria included: (1) previous valve surgery; (2) other moderate or severe heart valve disease; (3) cardiomyopathy with LVEF < 40\%; (4) persistent arrhythmias; (5) pregnancy terminated at $<20$ weeks gestation; (6) age less than 18 years; (7) presence of other medical comorbidities; and (8) poor image quality such that comprehensive echocardiographic assessment of left ventricular function and semi-automated GLS analysis could not be performed. For the control group, healthy age-matched women with a singleton pregnancy who were referred to the COB clinic with comprehensive echocardiography at the time of referral but found to have no evidence of significant cardiac disease were enrolled. All patients provided written consent and approval was obtained from the University of British Columbia's Research Ethics Board.

\section{Data Collection}

Baseline clinical data for cases and controls were obtained through electronic chart review. For all women, the following data were recorded: maternal age, parity, pre-pregnancy height and weight, baseline pre-pregnancy or early pregnancy vital signs (blood pressure, heart rate), anatomic details of cardiovascular disease (study group), cardiac surgical/interventional history, baseline New York Heart Association functional class and medication history. When available, obstetric and labour/delivery information was also collected. 


\section{Outcomes}

Adverse events during the ante-, peri-, and postpartum periods were classified as maternal cardiac, obstetrical, and fetal/neonatal. Two physicians (JG, AC) blinded to the women's baseline characteristics independently verified adverse events. Adverse cardiac events were defined as any of the following: left sided heart failure (HF) defined as pulmonary edema documented by chest radiograph or crackles heard over at least one third of posterior lung fields and jugular venous distension, right-sided HF, sustained atrial or ventricular tachyarrhythmias requiring treatment, stroke or transient ischemic attack, cardiac thromboembolism, myocardial infarction, cardiac arrest, or cardiac death. Obstetrical outcomes were defined as gestational hypertension, pre-eclampsia or eclampsia, hemorrhage, and premature rupture of membranes. Fetal and neonatal complications were defined as miscarriages, premature birth ( $<37$ weeks gestation), smallfor-gestational-age birth weight ( $<10$ th percentile for gestational age and sex or $<2500$ g), neonatal ICU admission, fetal death (after 20 weeks gestation and before birth), or neonatal death (from birth to age 28 days).

\section{Echocardiographic Examination}

Comprehensive transthoracic echocardiography was performed using Philips IE 33 system (Philips Medical Systems, Bothell, WA, USA). Images were stored and analyzed using Syngo software platform (Siemens Medical Solutions, MI, US). Standard echocardiographic parameters of left atrial volume; LV size and systolic and diastolic function; LVOT and aortic valve (AV) gradients and AV area were measured by the primary reader $(\mathrm{AC})$ under the guidance of an experienced echocardiographer (JG) according to the recommendations of American Society of Echocardiography (ASE) guidelines ${ }^{13,14}$.

For left ventricular global longitudinal strain analysis (GLS), Tomtec Cardiac Performance Analysis version 1.3.0.91 was used (Unterschliessheim, Germany). The software detects lateral and septal walls and divides each into three segments (basal, mid, and apical) to calculate the strain via speckle tracing. An average strain for entire LV in apical four chamber, apical two chamber, and apical three chamber views were used to calculate the GLS. Strain measurement was accepted after visual inspection and when the software demonstrated adequate tracking. If tracking was suboptimal, the endocardial border was manually retraced. Ten subjects were randomly selected to calculate the interobserver variability between the measurements of two independent investigators (AC, JG). Both investigators were blinded to each result.

\section{Statistical Analysis}

Mean \pm standard deviation and numbers (percentages) summarized continuous and categorical variables, respectively, for baseline characteristics measurements. Mean \pm standard deviation are presented for echocardiographic parameters through pregnancy. Echocardiographic parameters averaged for the $2^{\text {nd }} / 3^{\text {rd }}$ trimester values were compared for cases vs. controls with one way ANOVA analysis. Overall trend of echocardiographic parameters over the course of pregnancy was determined by mixed effects regression analysis for the cases.

\section{RESULTS}

\section{Baseline characteristics:}

During the study period, 117 patients with diagnosis of native LVOTO/AS were seen in the Cardiac Obstetrics Clinic. A total of 34 pregnancies fulfilled our study criteria. A majority of patients were excluded due to the lack of serial TTE studies $(n=64)$. Other reasons for exclusion were presence of other cardiac and medical comorbidities $(n=49)$ or early termination of pregnancy $<20$ weeks $(n=4)$. The patient baseline characteristics are summarized in Table 1. The cases had the following diagnoses: bicuspid aortic valve (18, $53 \%$ ); bicuspid aortic valve/aortic coarctation (14, 41\%); sub-valvular aortic stenosis (1, 3\%) and bicuspid aortic valve/sub-valvular stenosis $(1,3 \%)$.

All of the controls were NYHA I at the time of pregnancy. The control group had the following referral diagnoses: murmur (9, 26\%); presyncope (4, 12\%); palpitations (14, 41\%); electrocardiogram abnormalities 
$(2,6 \%)$; screening due to family history $(5,15 \%)$. The case/control groups were similar in age, pre-or early pregnancy blood pressure/heart rate and BMI.

\section{Echocardiographic characteristics:}

The echocardiographic changes in the LVOTO/AS group over the course of pregnancy and post-partum are shown in Table 2. In the LVOTO/AS group, there was an overall increase in the aortic valve peak gradient from preconception to the $3^{\text {rd }}$ trimester (Table 3 and Figure 1). The left ventricular and left atrial size increased and left ventricular ejection fraction decreased overall from preconception to the $3^{\text {rd }}$ trimester (Table 3 and Figure 1). The left ventricular GLS, however, increased over this time.

The averaged $2^{\text {nd }} / 3^{\text {rd }}$ trimester left ventricular dimension, left ventricular volume, cardiac output and aortic valve peak gradient were significantly increased in the pregnant LVOTO/AS group as compared to pregnant controls (Table 2). LVEF, left ventricular diastolic parameters and left ventricular global longitudinal strain were similar to between LVOTO/AS and control groups. However, in the sub-group of LVOTO/AS pregnant women with $>$ moderate $(\mathrm{n}=8)$ vs. $<$ moderate LVOTO $/ \mathrm{AS}(\mathrm{n}=26)$, averaged $2^{\text {nd }} / 3^{\text {rd }}$ trimester LVEF was lower $(51+-12 \%$ vs. $58+-4 \%, \mathrm{p}=0.02)$ and GLS was lower $(-19.5+-2.8$ vs. $-21.2+-2.4, \mathrm{p}=0.05)$.

\section{Adverse Maternal and Fetal/Neonatal Outcomes:}

All women in both LVOTO/AS and control groups were asymptomatic at baseline. There were no adverse maternal cardiac outcomes in the LVOTO/AS group (Table 4). Two women in the control group had supraventricular tachycardia during $2^{\text {nd }}$ trimester of their pregnancy (Table 4). Obstetrical outcomes were similar between the two groups, although a trend to increased rate of gestational hypertension, miscarriage, and pre-term deliveries were observed. Three adverse fetal events occurred in the LVOTO/AS group and none in the control group (Table 4).

\section{DISCUSSION}

In the current study, we aimed to characterize gestational changes in LVOTO/AS Doppler gradients and $\mathrm{LV}$ mechanics in women with LVOTO/AS as compared to pregnant controls and to assess the relationship with pregnancy outcomes. In our cohort of asymptomatic women with overall moderate LVOTO/AS, we found that AV peak gradient, left ventricular size and left atrial size increased over the course of pregnancy compared to controls. Although left ventricular function and mechanics were preserved in this cohort, there were dynamic changes over pregnancy with a trend to declining LVEF and small increase in GLS over the course of pregnancy. We also found that in this cohort of women with a range of LVOTO/AS, left ventricular size parameters, $\mathrm{CO}$, and $\mathrm{AV}$ gradients were significantly increased as compared to controls. Although there was no overall significant difference in left ventricular function and mechanics between all LVOTO/AS cases and controls, there was certainly a lower LVEF and GLS among those with moderate or greater LVOTO/AS as compared to controls. Pregnancy was well tolerated in all women with LVOTO/AS in this study with no deterioration in functional status or cardiac decompensation.

Studies focusing on sequential changes in LV function and mechanics over the course of normal pregnancies have been limited but would suggest no significant change occurs. Several older studies have shown that LVEF by $2 \mathrm{D}$ echocardiography remained stable during a normal pregnancy ${ }^{21-24}$. One study of a healthy pregnant cohort using 3D echocardiography observed a slight reduction in LVEF in late pregnancy with return to baseline at postpartum ${ }^{25}$. In another study of 36 healthy women, Sengupta and colleagues showed that global longitudinal and circumferential strain decreased while the radial strain increased during pregnancy, and postulated that these counterbalancing changes served to maintain the overall $\mathrm{LVEF}^{26}$. To our knowledge, only 2 studies have evaluated gestational changes in AV Doppler gradient and LV function and mechanics in women with LVOTO/AS. In a study of 6 women with congenital AS, Samiei et al reported an increase in the AV peak gradient from first trimester to third trimester $(30.8+-12.1 \text { to } 38+-19.5)^{9}$. Left ventricular function was not evaluated in this study. In a separate study, Tzemos et al. assessed 10 women with at least moderate congenital AS, and found that AV peak gradient rose from $59+-7 \mathrm{mmHg}$ (prepartum) to 70 +$9 \mathrm{mmHg}$ (antepartum) ${ }^{8}$. This group also assessed left ventricular mechanics, and found that LVEF and left 
ventricular longitudinal strain remained unchanged.

Our larger case control study similarly shows that AV gradients and LV and LA volumes increase over the course of pregnancy and significantly more in the LVOTO/AS cases as compared to pregnant controls. This is an important observation as clinicians should expect that gradients and cardiac volumes will increase across the spectrum of LVOTO/AS severity and to a greater degree than seen in pregnancies without structural heart disease. It is important to note that our cohort consisted of mostly mild LVOTO/AS (26/34, 76\%). Left ventricular function and mechanics remained in the normal range over the course of LVOTO/AS pregnancies, although LVEF trended to decline even in this cohort with milder forms of LVOTO/AS.

Numerous studies outside of pregnancy have demonstrated that increasing LVOTO/AS and the consequent LVH leads to impaired compliance, high filling pressures, and eventual replacement of interstitial space with reactive fibrosis ${ }^{27-31}$. In patients with AS, left ventricular GLS has been shown to detect this adverse remodeling before LVEF declines, and further deteriorates over time ${ }^{15,16,18,27}$. These changes certainly can complicate the hemodynamic adaptations required for an event free pregnancy.

Pregnancy with pre-existing significant left heart obstruction has been shown to be associated with increased risk of maternal cardiac events, as well as adverse obstetrical and fetal/neonatal outcomes ${ }^{32}$. Presence of a fixed obstruction and the reduced ability to augment stroke volume in setting of an increased physiologic demand of pregnancy is believed to be the mechanism for decompensation in women with LVOTO/AS ${ }^{10,26,33}$. Despite changes in cardiac size and trends to a declining LVEF, there were no adverse cardiac events in our study's LVOTO/AS group. This is likely due to the fact that LV function and mechanics remained in the normal range over the course of pregnancy for this entire cohort with mostly mild LVOTO/AS. An important observation is that LV function and mechanics were significantly lower in the moderate or greater LVOTO/AS group as compared to milder LVOTO/AS although still in the normal range. This would suggest that changes in function and mechanics likely play a role in cardiac decompensation in cases of significant LVOTO/AS with clinically relevant decline in LV function and mechanics. There was a trend to increased rate of gestational hypertension which has been previously documented among women with aortic coarctation. Finally, more miscarriage and preterm deliveries occurred in the study group, both of which are common fetal/neonatal complication encountered among woman with structural heart disease.

\section{Study limitations:}

This was a retrospective study, and therefore there was considerable variation in the timing of echocardiographic studies. However clinical practice would dictate timing to coincide with trimester. At our centre, it is a routine practice to obtain a baseline echocardiogram at the time of the referral and also a repeat echocardiogram during $2^{\text {nd }}$ trimester in women with LVOTO/AS. This likely mitigates some of the issues surrounding potential selection bias. Secondly, our study had a very small number of women with moderate or greater LVOTO/AS. This may potentially explain why the event rates for obstetrical and fetal/neonatal outcomes were also low. Finally, we assessed only the longitudinal strain, without measuring the circumferential or the radial strain. However, we feel that the longitudinal strain is the most clinically relevant marker, and the other types of strain are less applicable in clinical practice.

\section{CONCLUSION}

Among pregnant women with even milder forms of LVOTO/AS, increases in cardiac volumes and AV gradients can be expected over the course of pregnancy and to a greater degree than in pregnant women without structural heart disease. Despite this, LV function and mechanics remain in the normal range with LV function showing a trend to decline over the course of pregnancy. No adverse cardiac events were observed in this cohort. Significant LVOTO/AS is associated with reduced LV function and mechanics as compared to mild LVOTO/AS, and in the event of clinically relevant reduction, would likely account for adverse events. This warrants further study with a focus on sequential LV function/mechanics assessment over the course of pregnancy among those with only significant LVOTO/AS.

\section{FUNDING}


This research did not receive any specific grant from funding agencies in the public, commercial, or not-forprofit sectors.

\section{AUTHOR CONTRIBUTIONS}

SAC contributed to the study protocol, data collection and interpretation, and drafting of the manuscript. JG contributed to the overall study concept/design, statistical analysis, and the manuscript. PK and MJ contributed to the data collection. MK and VR reviewed the manuscript for critical revision.

\section{REFERENCES}

1. Lewin MB, McBride KL, Pignatelli R, Fernbach S, Combes A, Menesses A, et al. Echocardiographic evaluation of asymptomatic parental and sibling cardiovascular anomalies associated with congenital left ventricular outflow tract lesions. Pediatrics. 2004 Sep;114(3):691-6.

2. Loffredo CA, Chokkalingam A, Sill AM, Boughman JA, Clark EB, Scheel J, et al. Prevalence of congenital cardiovascular malformations among relatives of infants with hypoplastic left heart, coarctation of the aorta, and d-transposition of the great arteries. Am J Med Genet A. 2004 Jan 30;124A(3):225-30.

3. Aboulhosn Jamil, Child John S. Left Ventricular Outflow Obstruction. Circulation. 2006 Nov $28 ; 114(22): 2412-22$.

4. Shikany AR, Parrott A, James J, Madueme P, Nicole Weaver K, Cassidy C, et al. Left ventricular outflow tract obstruction: Uptake of familial cardiac screening and parental knowledge from a single tertiary care center. J Genet Couns. 2019 Aug;28(4):779-89.

5. Melchiorre K, Sharma R, Khalil A, Thilaganathan B. Maternal Cardiovascular Function in Normal Pregnancy: Evidence of Maladaptation to Chronic Volume Overload. Hypertens Dallas Tex 1979. 2016 Apr;67(4):754-62.

6. Nanna Michael, Stergiopoulos Kathleen. Pregnancy Complicated by Valvular Heart Disease: An Update. J Am Heart Assoc. 3(3):e000712.

7. Elkayam U, Bitar F. Valvular Heart Disease and Pregnancy: Part I: Native Valves. J Am Coll Cardiol. 2005 Jul 19;46(2):223-30.

8. Tzemos N, Silversides CK, Carasso S, Rakowski H, Siu SC. Effect of pregnancy on left ventricular motion (twist) in women with aortic stenosis. Am J Cardiol. 2008 Mar 15;101(6):870-3.

9. Samiei N, Amirsardari M, Rezaei Y, Parsaee M, Kashfi F, Hantoosh Zadeh S, et al. Echocardiographic Evaluation of Hemodynamic Changes in Left-Sided Heart Valves in Pregnant Women With Valvular Heart Disease. Am J Cardiol. 2016 01;118(7):1046-52.

10. Siegmund AS, Pieper PG, Mulder BJM, Sieswerda GT, van Dijk APJ, Roos-Hesselink JW, et al. Doppler gradients, valve area and ventricular function in pregnant women with aortic or pulmonary valve disease: Left versus right. Int J Cardiol. 2020 01;306:152-7.

11. Jurcut R, Wildiers H, Ganame J, D'hooge J, De Backer J, Denys H, et al. Strain rate imaging detects early cardiac effects of pegylated liposomal Doxorubicin as adjuvant therapy in elderly patients with breast cancer. J Am Soc Echocardiogr Off Publ Am Soc Echocardiogr. 2008 Dec;21(12):1283-9.

12. Nesbitt GC, Mankad S, Oh JK. Strain imaging in echocardiography: methods and clinical applications. Int J Cardiovasc Imaging. 2009 Apr;25 Suppl 1:9-22.

13. Marwick TH. Methods used for the assessment of LV systolic function: common currency or tower of Babel? Heart Br Card Soc. 2013 Aug;99(15):1078-86.

14. Helle-Valle T, Crosby J, Edvardsen T, Lyseggen E, Amundsen BH, Smith H-J, et al. New noninvasive method for assessment of left ventricular rotation: speckle tracking echocardiography. Circulation. 2005 Nov $15 ; 112(20): 3149-56$. 
15. Vollema EM, Sugimoto T, Shen M, Tastet L, Ng ACT, Abou R, et al. Association of Left Ventricular Global Longitudinal Strain With Asymptomatic Severe Aortic Stenosis: Natural Course and Prognostic Value. JAMA Cardiol. 2018 Sep 1;3(9):839-47.

16. Cosyns B, Vannan MA. Global longitudinal strain in severe aortic stenosis. Eur Heart J Cardiovasc Imaging. 2020 Oct 20;21(11):1259-61.

17. Zhu D, Ito S, Miranda WR, Nkomo VT, Pislaru SV, Villarraga HR, et al. Left Ventricular Global Longitudinal Strain Is Associated With Long-Term Outcomes in Moderate Aortic Stenosis. Circ Cardiovasc Imaging. 2020 Apr;13(4):e009958.

18. Bottaro G, Zappulla P, Deste W, Fama F, Agnello F, Trovato D, et al. Severe Aortic Valve Stenosis: Symptoms, Biochemical Markers, and Global Longitudinal Strain. J Cardiovasc Echography. 2020 Sep;30(3):154-61.

19. Lang RM, Badano LP, Mor-Avi V, Afilalo J, Armstrong A, Ernande L, et al. Recommendations for Cardiac Chamber Quantification by Echocardiography in Adults: An Update from the American Society of Echocardiography and the European Association of Cardiovascular Imaging. J Am Soc Echocardiogr. 2015 Jan;28(1):1-39.e14.

20. Baumgartner H, Hung J, Bermejo J, Chambers JB, Edvardsen T, Goldstein S, et al. Recommendations on the Echocardiographic Assessment of Aortic Valve Stenosis: A Focused Update from the European Association of Cardiovascular Imaging and the American Society of Echocardiography. J Am Soc Echocardiogr. 2017 Apr 1;30(4):372-92.

21. Geva T, Mauer MB, Striker L, Kirshon B, Pivarnik JM. Effects of physiologic load of pregnancy on left ventricular contractility and remodeling. Am Heart J. 1997 Jan;133(1):53-9.

22. Siu SC, Colman JM. Heart disease and pregnancy. Heart Br Card Soc. 2001 Jun;85(6):710-5.

23. Gilson GJ, Samaan S, Crawford MH, Qualls CR, Curet LB. Changes in hemodynamics, ventricular remodeling, and ventricular contractility during normal pregnancy: a longitudinal study. Obstet Gynecol. 1997 Jun;89(6):957-62.

24. Savu O, Jurcut R, Giuşcă S, van Mieghem T, Gussi I, Popescu BA, et al. Morphological and functional adaptation of the maternal heart during pregnancy. Circ Cardiovasc Imaging. 2012 May 1;5(3):289-97.

25. Cong J, Fan T, Yang X, Squires JW, Cheng G, Zhang L, et al. Structural and functional changes in maternal left ventricle during pregnancy: a three-dimensional speckle-tracking echocardiography study. Cardiovasc Ultrasound. 2015 Jan 27;13:6.

26. Sengupta SP, Bansal M, Hofstra L, Sengupta PP, Narula J. Gestational changes in left ventricular myocardial contractile function: new insights from two-dimensional speckle tracking echocardiography. Int J Cardiovasc Imaging. 2017 Jan;33(1):69-82.

27. Dahl JS, Magne J, Pellikka PA, Donal E, Marwick TH. Assessment of Subclinical Left Ventricular Dysfunction in Aortic Stenosis. JACC Cardiovasc Imaging. 2019 Jan;12(1):163-71.

28. Hoffmann R, Altiok E, Friedman Z, Becker M, Frick M. Myocardial Deformation Imaging by TwoDimensional Speckle-Tracking Echocardiography in Comparison to Late Gadolinium Enhancement Cardiac Magnetic Resonance for Analysis of Myocardial Fibrosis in Severe Aortic Stenosis. Am J Cardiol. 2014 Oct $1 ; 114(7): 1083-8$.

29. Chin CWL, Everett RJ, Kwiecinski J, Vesey AT, Yeung E, Esson G, et al. Myocardial Fibrosis and Cardiac Decompensation in Aortic Stenosis. JACC Cardiovasc Imaging. 2017 Nov 1;10(11):1320-33.

30. Dweck MR, Joshi S, Murigu T, Alpendurada F, Jabbour A, Melina G, et al. Midwall Fibrosis Is an Independent Predictor of Mortality in Patients With Aortic Stenosis. J Am Coll Cardiol. 2011 Sep 13;58(12):1271-9. 
31. Podlesnikar T, Delgado V, Bax JJ. Cardiovascular magnetic resonance imaging to assess myocardial fibrosis in valvular heart disease. Int J Cardiovasc Imaging. 2018 Jan 1;34(1):97-112.

32. Fuchs M, Zaidi AN, Rose J, Sisk T, Daniels CJ, Bradley EA. Location matters: left heart obstruction in pregnancy. Eur J Obstet Gynecol Reprod Biol. 2016 Jan;196:38-43.

33. Narayanan M, Elkayam U, Naqvi TZ. Echocardiography in Pregnancy: Part 2. Curr Cardiol Rep. 2016 Sep;18(9):90.

FIGURE 1. Echocardiographic changes over the course of pregnancy in women with LVOTO/AS and the overall regression line (red line). Each line represents an individual LVOTO/AS case, with dots representing each visit. Time points $\# 1=$ pre-pregnancy $\# 2=1^{\text {st }}$ trimester $\# 3=2^{\text {nd }}$ trimester $\# 4=3^{\text {rd }}$ trimester

\section{TABLES}

Table 1. Baseline characteristics

\begin{tabular}{lll}
\hline Variable & Control group $(\mathbf{n}=\mathbf{3 4})$ & LVOTO/AS group (n \\
\hline Age (years) & $30.5+4.9$ & $30.6+4.8$ \\
Systolic blood pressure $(\mathbf{m m H g}$ & $113.2+8.6$ & $112.5+12.6$ \\
Diastolic blood pressure ( $\mathbf{m m H g})$ & $63.9+7.1$ & $67.7+10.5$ \\
Body surface area $\left(\mathrm{kg} / \mathbf{m}^{\mathbf{2}}\right)$ & $1.8+0.1$ & $1.8+0.1$ \\
Body mass index $\left(\mathbf{m}^{2}\right)$ & $25.0+3.1$ & $26.2+4.8$ \\
Cardiac medications Beta blocker Calcium channel blocker & $11(32 \%) 1(3 \%)$ & $5(15 \%) 0(0 \%)$ \\
\hline
\end{tabular}

Data are expressed as $\mathrm{n}(\%)$ or mean $\pm \mathrm{SD}$

Table 2. Echocardiographic changes during pregnancy in women with LVOTO/AS and controls*

\begin{tabular}{|c|c|c|c|c|c|c|c|c|}
\hline Variable & $\begin{array}{l}\text { Pre- } \\
\text { Pregnancy }\end{array}$ & $\begin{array}{l}1^{\text {st }} \\
\text { Trimester }\end{array}$ & $\begin{array}{l}2^{\text {nd }} \\
\text { Trimester }\end{array}$ & $\begin{array}{l}3^{\text {rd }} \\
\text { Trimester }\end{array}$ & $\begin{array}{l}\text { Post- } \\
\text { Partum }\end{array}$ & $\begin{array}{l}\text { Avg } \\
\text { LVOTO/AS }\end{array}$ & $\begin{array}{l}\text { Avg } \\
\text { controls }\end{array}$ & $\mathrm{p}^{\wedge}$ \\
\hline $\begin{array}{l}\text { Heart } \\
\text { rate, } \\
\text { bpm }\end{array}$ & $71(11)$ & $69(11)$ & $73(12)$ & $77(15)$ & $62(7)$ & $77(14)$ & $78(15)$ & 0.78 \\
\hline $\begin{array}{l}\text { LVEDD, } \\
\text { mm }\end{array}$ & $45(3)$ & $47(5)$ & $49(6)$ & $50(6)$ & $45(16)$ & $49(6)$ & $45(5)$ & 0.02 \\
\hline $\begin{array}{l}\text { LVEDV, } \\
\text { ml }\end{array}$ & $131(11)$ & $134(31)$ & $137(26)$ & $141(23)$ & $129(36)$ & $138(26)$ & $126(26)$ & 0.88 \\
\hline $\begin{array}{l}\text { LVESV, } \\
\mathrm{ml}\end{array}$ & $55(11)$ & $53(16)$ & $58(14)$ & $63(15)$ & $55(11)$ & $60(14)$ & $52(12)$ & 0.03 \\
\hline $\begin{array}{l}\text { LVEF, } \\
\%\end{array}$ & $59(7)$ & $61(6)$ & $57(8)$ & $56(6)$ & $59(6)$ & $56(7)$ & $57(11)$ & 0.81 \\
\hline $\begin{array}{l}\mathrm{CO}, \\
\mathrm{l} / \mathrm{min}\end{array}$ & $4.8(2.0)$ & $5.6(1.7)$ & $6.2(5.5)$ & $5.9(1.7)$ & $4.5(1.7)$ & $5.7(1.6)$ & $4.2(1.5)$ & 0.001 \\
\hline $\begin{array}{l}\text { LAV, } \\
\text { ml }\end{array}$ & $43(9)$ & $47(7)$ & $53(13)$ & $55(12)$ & $53(13)$ & $54(12)$ & $53(15)$ & 0.86 \\
\hline $\begin{array}{l}\text { Mitral } \\
\text { E/a }\end{array}$ & $1.5(0.4)$ & $1.9(0.8)$ & $1.7(0.5)$ & $1.5(0.4)$ & $1.8(0.4)$ & $1.7(0.5)$ & $1.7(0.6)$ & 0.96 \\
\hline $\begin{array}{l}\text { E' } \\
\text { medial }\end{array}$ & $\begin{array}{l}10.3 \\
(1.5)\end{array}$ & $9.2(1.7)$ & $\begin{array}{l}10.2 \\
(2.6)\end{array}$ & $9.5(2.4)$ & $9.0(2.1)$ & $\begin{array}{l}10.1 \\
(2.7)\end{array}$ & $\begin{array}{l}10.7 \\
(2.7)\end{array}$ & 0.45 \\
\hline
\end{tabular}




\begin{tabular}{lllllllll}
\hline & $\begin{array}{l}\text { Pre- } \\
\text { Variable }\end{array}$ & $\begin{array}{l}\mathbf{1}^{\text {st }} \\
\text { Pregnancy }\end{array}$ & Trimester & $\begin{array}{l}\mathbf{2}^{\text {nd }} \\
\text { Trimester }\end{array}$ & $\begin{array}{l}\mathbf{3}^{\text {rd }} \\
\text { Trimester }\end{array}$ & $\begin{array}{l}\text { Post- } \\
\text { Partum }\end{array}$ & $\begin{array}{l}\text { Avg } \\
\text { LVOTO/AS controls }\end{array}$ & $\begin{array}{c}\text { Avg } \\
\mathrm{p}^{\wedge}\end{array}$ \\
\hline E' & 13.4 & 13.7 & 15.0 & 13.0 & 12.8 & 14.5 & 14.3 & 0.89 \\
lateral & $(3.6)$ & $(4.1)$ & $(3.4)$ & $(2.9)$ & $(3.0)$ & $(3.2)$ & $(4.7)$ & \\
LVOT & $5.1(1.4)$ & $3.8(1.7)$ & $6.6(9.4)$ & $7.4(9.8)$ & $4.1(1.3)$ & 8.0 & $4.6(1.7)$ & 0.14 \\
PW & & & & & & $(10.8)$ & & \\
AV PG & 21.3 & 23.5 & 28.0 & 26.0 & 22.4 & 27.4 & $9.0(2.7)$ & $<\mathbf{0 . 0 0 1}$ \\
& $(14.7)$ & $(14.1)$ & $(19.8)$ & $(17.4)$ & $(17.1)$ & $(19.8)$ & & \\
GLS & -22.1 & -22.5 & -21.0 & -19.7 & -21.9 & -20.8 & -21.8 & 0.10 \\
& $(1.8)$ & $(2.2)$ & $(2.5)$ & $(3.1)$ & $(2.4)$ & $(2.6)$ & $(1.8)$ & \\
\hline
\end{tabular}

* mean (SD), ^ LVOTO/AS cases vs. control (comparison of average of $2^{\text {nd }} / 3^{\text {rd }}$ trimester)

Table 3. Echocardiographic changes in LVOTO/AS cases over pregnancy

\begin{tabular}{lll}
\hline & Estimate $(\mathbf{9 5 \%} \mathbf{C I})$ & $\mathrm{P}$ \\
\hline HR & $2.13(-0.19,4.44)$ & 0.07 \\
LVEDD & $0.62(-0.09,1.32)$ & 0.08 \\
LVEDV & $2.12(-2.19,6.43)$ & 0.32 \\
LVEF & $-1.59(-3.28,0.10)$ & 0.06 \\
CO & $1.14(-2.41,4.68)$ & 0.52 \\
LA_vol & $3.07(0.60,5.53)$ & $\mathbf{0 . 0 2}$ \\
Mitral_E_A & $-0.04(-0.15,0.08)$ & 0.52 \\
TDI__medial_e & $-0.21(-0.70,0.29)$ & 0.39 \\
TDI_lateral_e & $-0.32(-1.04,0.40)$ & 0.37 \\
LVOT_peak_gradient & $0.35(-0.10,0.80)$ & 0.12 \\
AV_peak_gradient & $2.11(0.31,3.91)$ & $\mathbf{0 . 0 2}$ \\
LV_GLS & $0.68(0.15,1.21)$ & $\mathbf{0 . 0 1}$ \\
\hline
\end{tabular}

Table 4. Maternal and Fetal/Neonatal Outcomes

\begin{tabular}{|c|c|c|c|}
\hline Variable & Control group $\mathrm{n}=34(\%)$ & $\begin{array}{l}\text { LVOTO/AS group } \mathrm{n}= \\
34(\%)\end{array}$ & $P$ \\
\hline $\begin{array}{l}\text { Gestational age at } \\
\text { delivery (years) }\end{array}$ & 39 & 37.7 & 0.73 \\
\hline Birth weight (g) & 3373.0 & 3363.7 & 0.48 \\
\hline Mode of delivery: (\%) & $12(35.3) 5(14.7) 6$ & $14(41.2) 10(29.4) 3$ & $0.800 .240 .47-$ \\
\hline Spontaneous delivery & $(17.6) 5(14.7)$ & $(8.8) 5(14.7)$ & \\
\hline \multicolumn{4}{|l|}{ Elective C-section } \\
\hline \multicolumn{4}{|l|}{ Emergency C-section } \\
\hline \multicolumn{4}{|l|}{$\begin{array}{l}\text { Forceps / vacuum } \\
\text { assisted }\end{array}$} \\
\hline $\begin{array}{l}\text { Any adverse maternal } \\
\text { events: Heart failure }\end{array}$ & $2(5.9) 02(5.9) 000$ & $\begin{array}{lllllllllll}0 & 0 & 0 & 0 & 0 & 0\end{array}$ & 0.47 \\
\hline \multicolumn{4}{|l|}{$\begin{array}{l}\text { events: Heart Ianure } \\
\text { Arrythmia }\end{array}$} \\
\hline \multicolumn{4}{|l|}{$\begin{array}{l}\text { Hospitalization due } \\
\text { cardiac cause }\end{array}$} \\
\hline $\begin{array}{l}\text { Pre-eclampsia Deaths } \\
\text { due to any cause }\end{array}$ & & & \\
\hline
\end{tabular}




\begin{tabular}{|c|c|c|c|}
\hline Variable & Control group $\mathrm{n}=34(\%)$ & $\begin{array}{l}\text { LVOTO/AS group } \mathrm{n}= \\
34(\%)\end{array}$ & $P$ \\
\hline $\begin{array}{l}\text { Any obstetrical } \\
\text { complications: } \\
\text { Gestational diabetes } \\
\text { Gestational hypertension } \\
\text { Pre-eclampsia } \\
\text { Hemorrhage Premature } \\
\text { rupture of membranes } \\
\text { Other N/A }\end{array}$ & $\begin{array}{l}11(32.4) 4(11.8) 1(2.9) \\
1(2.9) 001 \\
\text { (chorioamnionitis) } 4\end{array}$ & $\begin{array}{l}9(26.5) 1(2.9) 4(11.8) 0 \\
1(2.9) 003\end{array}$ & 0.79 \\
\hline $\begin{array}{l}\text { Any fetal/neontal } \\
\text { complications } \\
\text { Miscarriage Preterm } \\
\text { delivery }(<37 \text { weeks }) \\
\text { Small for gestational age } \\
\left(<10^{\text {th }} \text { percentile for }\right. \\
\text { weight }) \text { Neonatal ICU } \\
\text { admission N/A }\end{array}$ & $5(14.7) 000005$ & $\begin{array}{l}5(14.7) 1(2.9) 2(5.9) 0 \\
02\end{array}$ & - \\
\hline
\end{tabular}

Data reported as n (\%) for categorical variables

\section{Hosted file}

Figure 1.pptx available at https://authorea.com/users/420691/articles/526973-pregnancyrelated-changes-in-doppler-gradients-and-left-ventricular-mechanics-in-women-withsubvalvular-or-valvular-aortic-stenosis 